\title{
A Case of Adrenal Insufficiency Due to Acquired Hypothalamic CRH Deficiency
}

\author{
EIJUN NISHIHARA, HIRONORI KIMURA, TADAHIKO ISHIMARU, TAKESHI KIRIYAMA, \\ NAOKATA YOKOYAMA, SHUNICHI YAMASHITA*, AND SHIgENOBU NAGATAKI \\ The First Department of Internal Medicine, and *Department of Cell Physiology, Atomic Disease Institute, \\ Nagasaki University School of Medicine, Nagasaki 852, Japan
}

\begin{abstract}
A 40-year-old woman with adrenal insufficiency was clinically diagnosed and examined with human corticotropin releasing hormone $(\mathrm{CRH})$. This patient with secondary hypo-adrenalism has shown a normal serum cortisol response to exogenous ACTH administration and has been examined with CRH, lysine-vasopressin (LVP) and insulin tolerance test (ITT), respectively. Success in secreting ACTH in response to both CRH and LVP tests, but not ITT, suggests that this disorder was possibly due to a hypothalamic CRH deficiency rather than pituitary corticotroph dysfunction. A combination of the $\mathrm{CRH}$ test and ITT has come to play an increasingly significant role in the diagnosis and differential diagnosis of isolated ACTH deficiency syndrome.
\end{abstract}

Key words: Corticotropin releasing hormone (CRH), ACTH, Hypothalamus, Adrenal insufficiency, Chronic thyroiditis

(Endocrine Journal 44: 121-126, 1997)

PATIENTS with cortisol deficiency secondary to dysfunction above the level of the adrenal glands may have a functional defect at the level of the pituitary or the hypothalamus. Isolated ACTH deficiency is a rare disorder and causes adrenal insufficiency, which was first reported by Steinberg et al. in 1954 [1]. Most cases of isolated ACTH deficiency reported are caused by ACTH deficit at the level of the pituitary gland [2], but corticotropin-releasing hormone (CRH) deficiency in the hypothalamus could also cause isolated ACTH deficiency [3]. The differential diagnosis of pituitary deficit and hypothalamic deficit has not yet been completely established. $\mathrm{CRH}$, either synthesized or extracted from an ovine source, has been reported to lead to a rapid rise in plasma

\section{Received: April 19, 1996}

Accepted: October 17, 1996

Correspondence to: Dr. Shigenobu NAGATAKI, The First Department of Internal Medicine, Nagasaki University School of Medicine, 1-7-1 Sakamoto, Nagasaki 852, Japan
ACTH levels after being given as an acute bolus injection [4]. With the recent availability of human recombinant CRH [5], it is now possible to better tell whether a hypothalamic or pituitary deficit is responsible for the isolated ACTH deficiency syndrome.

Herein we report a patient with isolated ACTH deficiency in whom CRH test, lysine-vasopressin (LVP) test and insulin tolerance test (ITT) were performed, and showed normal response of ACTH to a CRH test, suggesting hypothalamic $\mathrm{CRH}$ deficiency.

\section{Case Report}

A 40-year-old Japanese woman had a long history of bronchial asthma and was sometimes treated for asthma with beta-adrenergic agonists, but she had never been treated by oral administration, injection or inhalation of corticosteroids. In 1972 she first experienced an 
episode of dizziness and syncopal attack. At that time a $24 \mathrm{~h}$ Holter's electrocardiogram (ECG) revealed no abnormal findings. After her marriage in 1985 , she gained $15 \mathrm{~kg}$ in weight in six months, and had progressive general fatigue throughout the day. In 1988, when she felt dizzy, low blood pressure (BP) (systolic $78 \mathrm{mmHg}$ ) was first pointed out. In May, 1994 she noted palpitation and paresthesia in the upper and lower limbs accompanied with cold sweats and tremor relieved by food intake. Hormonal evaluation revealed low ACTH $(12.0 \mathrm{pg} / \mathrm{ml})$ and an abnormally low serum cortisol level $(2.8 \mu \mathrm{g} / \mathrm{d} l)$. She also underwent examination by brain magnetic resonance imaging (MRI) and an electroencephalogram, which revealed no abnormal findings. In October, 1994 she was admitted to our hospital for further evaluation. Physical examination revealed $+26.5 \%$ obesity $(70.7 \mathrm{~kg}, 159.4 \mathrm{~cm})$, slightly enlarged thyroid gland, normal pigmentation of the skin and a supine blood pressure of $98 / 56 \mathrm{mmHg}$. Laboratory evaluation revealed slightly high $\gamma$ GTP (107 IU; normal range: 0-50) and LAP (109 IU; normal range: $40-100)$, positive antithyroglobulin autoantibody (TGHA; $\times 6400)$ and antimicrosomal autoantibody (MCHA; $\times 25600$ ). Fasting blood sugar was $82 \mathrm{mg} / \mathrm{d} l$ (normal range: 70-110) and hemoglobin $\mathrm{A}_{1 \mathrm{c}}\left(\mathrm{Hb}_{1 \mathrm{c}}\right)$ was $5.7 \%$ (normal range: 4.1-6.0). $75 \mathrm{~g}$ Oral glucose tolerance test and insulin sensitivity test revealed normal patterns. Antipituitary antibody, anti-adrenal cortex antibody, anti-glutamic acid decarboxylase (GAD) antibody and anti-islet cell antibody (ICA) were negative. Sellar X-ray and abdominal computed tomography (CT) were normal. Thyroid fine needle aspiration biopsy showed a marked lymphocytic infiltration, which is typical finding in Hashimoto's thyroiditis. Autonomic nerve function tests ( $R-R$ interval in ECG and Schellong's test) were normal. Her menstruation cycles were regular. She had never smoked or consumed alcohol. After examination, she was treated by oral administration of hydrocortisone ( $20 \mathrm{mg} /$ day). After the treatment symptoms such as easy fatigability, hypoglycemic attack and dizziness disappeared.

\section{Analytical Methods}

The studies were carried out while the patient was admitted to the Nagasaki University Hospital. Informed consent was obtained from the patient. Clinical examination, CT scan and MRI were performed. Plasma ACTH and serum cortisol profiles were determined while the patients remained in bed. Blood samples were obtained via an iv catheter which was placed in a forearm vein at least $60 \mathrm{~min}$ before the start of the the study. Plasma ACTH was measured with a commercial immunoradiometric assay (IRMA) kit from Nicols Institute (San Juan Capistrano, CA, USA). Serum cortisol levels were measured by a specific radioimmunoassay (RIA) (Cortisol Eiken kit, Eiken Chemical Co., Ltd., Tokyo, Japan). Urinary free cortisol (UFC) concentrations were measured by a specific RIA (SPAC-S Cortisol Kit; Daiichi Radioisotope Co., Ltd.). Normal ranges for plasma ACTH, serum cortisol, and UFC are 9.0-52.0 pg/ $\mathrm{ml}, 5.0-15.0 \mu \mathrm{g} / \mathrm{d} l$, and 38.7-174.0 $\mu \mathrm{g} / 24 \mathrm{~h}$, respectively. Serum TSH was measured by an RIA (RIA-gnost hTSH, Hoechist Japan Co., Tokyo, Japan). Serum $T_{4}, T_{3}\left(T_{4}\right.$ 'Eiken' RIA Kit, Ab Tube T3 RIA Kit, Eiken Chemical Co., Ltd., Tokyo, Japan), free $\mathrm{T}_{4}\left(\mathrm{FT}_{4}\right)$, free $\mathrm{T}_{3}\left(\mathrm{FT}_{3}\right)$ (MAb FT3 RIA Kit, MAb $\mathrm{FT}_{4}$ RIA Kit, Amersham, UK) were measured with commercially available RIA kits. Anti-thyroglobulin (TGHA) and anti-microsomal (MCHA) autoantibodies were measured by the tanned red cell agglutination technique with commercially available kits (Thyroid test and Microsomal test, FujiRebio Co., Tokyo, Japan). Aldosterone (SPAC-S Aldosterone Kit; Daiichi Radioisotope Co., Ltd.), LH (SPAC-S LH Kit; Daiichi Radioisotope Co., Ltd.), FSH (SPAC-S FSH Kit; Daiichi Radioisotope Co., Ltd.), GH (HGH RIA Kit2; Dynabot Co., Tokyo, Japan), PRL (SPAC-S Prolactin Kit; Daiichi Radioisotope Co., Ltd.), Estradiol (Estradiol coat RIA; CIS Diagnostic Co.) were measured with commercially available RIA kits.

\section{Results}

The results of basal hormone level and anterior pituitary function tests in this patient are represented in Table 1 and Table 2, respectively. Plasma ACTH, serum cortisol and urinary excretion of free cortisol were abnormally low. And those findings in the independent examinations at the 
several different day showed the same tendency. As shown in Table 2 TRH test, LH-RH test and GH response to ITT showed almost normal patterns. MRI of the sella turcica and of the hypothalamus revealed no abnormal findings.

The patient showed a normal serum cortisol response to exogenous $\mathrm{ACTH}$ injection. The serum cortisol levels rose to $10.1 \mu \mathrm{g} / \mathrm{d} l$ at $30 \mathrm{~min}$ after ACTH administration ( $0.25 \mathrm{mg}$, i.v.). A peak rise in cortisol levels to $13.6 \mu \mathrm{g} / \mathrm{d} l$ was seen at $60 \mathrm{~min}$.

Figure 1 shows low response of ACTH and cortisol to insulin-induced hypoglycemia in this patient. A peak rise in ACTH levels to only 14.5 $\mathrm{pg} / \mathrm{ml}$ and in cortisol levels to only $4.1 \mu \mathrm{g} / \mathrm{d} l$ was observed $60 \mathrm{~min}$ after regular insulin $3.5 \mathrm{U}(0.05$ $\mathrm{U} / \mathrm{kg}$ ) administration.

LVP (10 U, i.m.) administration induced a peak rise in ACTH levels to $68.2 \mathrm{pg} / \mathrm{ml}$ at $30 \mathrm{~min}$ and in cortisol levels to $12.8 \mu \mathrm{g} / \mathrm{d} l$ at $60 \mathrm{~min}$ (Fig. 2).

A single administration of human CRH (100 $\mu \mathrm{g}$, i.v.) induced pronounced ACTH responses. The peak ACTH level was $105.8 \mathrm{pg} / \mathrm{ml}$ at $30 \mathrm{~min}$ and its recovery phase showed a slightly delayed pattern. The serum cortisol level also rose to 8.3 $\mu \mathrm{g} / \mathrm{d} l$ at $30 \mathrm{~min}$ after $\mathrm{CRH}$ stimulation (Fig. 3A). A slightly augmented ACTH response to CRH stimulation was seen after five successive days of CRH pretreatment (100 $\mu$ g, i.v./day). The peak ACTH level rose much more to $144.6 \mathrm{pg} / \mathrm{ml}$ and the cortisol level to $11.9 \mu \mathrm{g} / \mathrm{d} l$ at $30 \mathrm{~min}$ after $\mathrm{CRH}$ administration (Fig. 3B).

\section{Discussion}

The patient reported here had the clinical features of adrenal insufficiency. The hormonal deficiency was not adrenal in origin as demonstrated by the low plasma ACTH level and the rise in the serum cortisol level after exogenous ACTH administration. The biochemical and hormonal findings in the patient were similar to those observed in patients with isolated ACTH deficiency because of the intactness of other anterior pituitary hormone secretion. TSH hyperresponsiveness to TRH is frequently seen in patients with isolated ACTH deficiency. This is thought to be due to hypocortisolism and primary hypothyroidism. In our patient TSH hyperresponsiveness was, however, not detected probably due to very mild
Table 1. Basal hormone levels in a patient with $\mathrm{CRH}$ deficiency

\begin{tabular}{lccc}
\hline & & Hormone levels & Normal range \\
\hline ACTH & $(0800 \mathrm{~h})$ & 5.3 & $9.0-52.0 \mathrm{pg} / \mathrm{ml}$ \\
& $(2000 \mathrm{~h})$ & 5.3 & \\
Cortisol & $(0800 \mathrm{~h})$ & 1.4 & $5.0-15.0 \mu \mathrm{g} / \mathrm{d} l$ \\
& $(2000 \mathrm{~h})$ & 1.5 & \\
Aldosterone & 4.2 & $3.6-24.0 \mathrm{ng} / \mathrm{d} l$ \\
Urinary free cortisol & 33.8 & $38.7-174.0 \mu \mathrm{g} / \mathrm{day}$ \\
LH (follicular phase) & 4.6 & $0.9-15.5 \mathrm{mIU} / \mathrm{ml}$ \\
FSH (follicular phase) & 6.2 & $3.1-23.9 \mathrm{mIU} / \mathrm{ml}$ \\
GH & 0.5 & $<5.0 \mathrm{ng} / \mathrm{ml}$ \\
PRL & 8.4 & $1.4-14.6 \mathrm{ng} / \mathrm{ml}$ \\
TSH & 1.49 & $0.3-3.2 \mu \mathrm{U} / \mathrm{ml}$ \\
FT & 1.0 & $1.0-1.8 \mathrm{ng} / \mathrm{d} l$ \\
FT3 & 2.2 & $2.7-5.4 \mathrm{pg} / \mathrm{ml}$ \\
TGHA & $\times 1600$ & $<\times 100$ \\
MCHA & $\times 25600$ & $<\times 100$ \\
ADH & 2.8 & $0.3-4.2 \mathrm{pg} / \mathrm{ml}$ \\
Estradiol (follicular phase) & 39.5 & $25-100 \mathrm{pg} / \mathrm{ml}$ \\
\hline
\end{tabular}

TGHA, Thyroglobulin hemagglutination; MCHA, Microsome hemagglutination; $\mathrm{ADH}$, Antidiuretic hormone.

Table 2. Results of anterior pituitary function tests

\begin{tabular}{|c|c|c|c|c|}
\hline \multicolumn{5}{|l|}{ TRH test } \\
\hline Time (min) & $\mathrm{TSH}$ & $(\mu \mathrm{U} / \mathrm{ml})$ & PRL & $(\mathrm{ng} / \mathrm{ml})$ \\
\hline 0 & 2.23 & & 4.7 & \\
\hline 30 & 26.91 & & 69.4 & \\
\hline 60 & 20.89 & & 40.1 & \\
\hline 90 & 13.31 & & 22.2 & \\
\hline 120 & 9.12 & & 14.3 & \\
\hline \multicolumn{5}{|l|}{ LH-RH test } \\
\hline Time (min) & LH & $(\mathrm{mIU} / \mathrm{ml})$ & FSH & $(\mathrm{mIU} / \mathrm{ml})$ \\
\hline 0 & 2.3 & & 4.4 & \\
\hline 30 & 21.1 & & 7.1 & \\
\hline 60 & 20.2 & & 8.0 & \\
\hline 90 & 16.1 & & 8.2 & \\
\hline 120 & 12.9 & & 8.1 & \\
\hline \multicolumn{5}{|c|}{ GH response to ITT } \\
\hline Time (min) & $\mathrm{GH}$ & $(\mathrm{ng} / \mathrm{ml})$ & BS & $(\mathrm{mg} / \mathrm{d} l)$ \\
\hline 0 & 2.9 & & 90 & \\
\hline 15 & 1.2 & & 43 & \\
\hline 30 & 1.0 & & 36 & \\
\hline 60 & 11.9 & & 73 & \\
\hline 90 & 7.6 & & 82 & \\
\hline 120 & 7.7 & & 84 & \\
\hline
\end{tabular}

hypothyroidism. The unique finding which was the difference between the ACTH response in the $\mathrm{CRH}$ test and the insulin-induced hypoglycemia test points to the existence of an underlying defect 


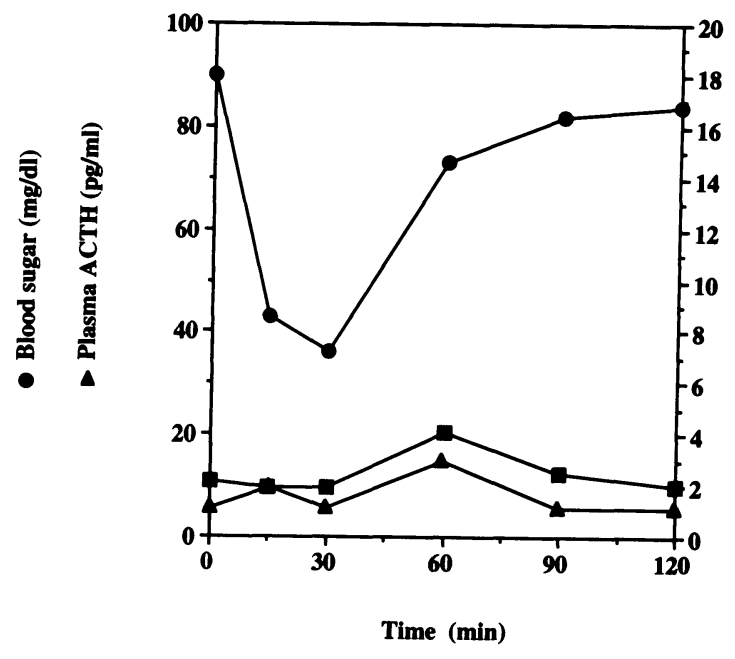

Fig. 1. Response to intravenous insulin $(0.05 \mathrm{U} / \mathrm{kg}, \mathrm{i} . \mathrm{v}$. administration. Insufficient increases were seen in plasma ACTH levels $(\boldsymbol{\Delta})$ and serum cortisol levels $(\square)$ in association with hypoglycemia.
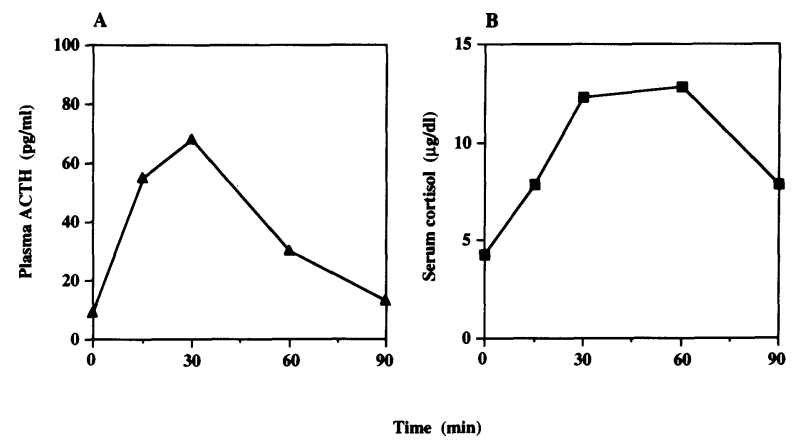

Fig. 2. Response to lysine vasopressin (10 U, i.m.) administration. Lysine vasopressin elicited an increase in plasma ACTH (A) and serum cortisol concentrations (B).

at the level of the hypothalamus, but the appreciable anatomical abnormality in hypothalamus was not detected by MRI scanning.

Isolated ACTH deficiency syndrome is a heterogeneous disorder with several etiologies. Nowadays an autoimmune process affecting the pituitary gland is thought to be a most common cause of this syndrome [2]. The presence of an anti-pituitary or anti-corticotroph antibody has been reported to be responsible for the absence of ACTH response to CRH in some cases of isolated ACTH deficiency [6, 7]. Antibodies reactive to pituitary cells were often detected not only in

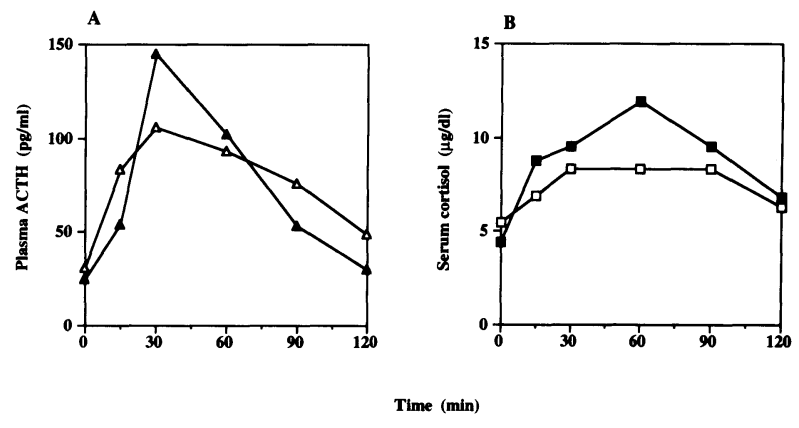

Fig. 3. Response of plasma $\mathrm{ACTH}$ (A) and serum cortisol concentrations (B) to a single administration of human CRH (100 $\mu$ g, i.v.) (open) and to human CRH $(100 \mu$ g,i.v.) administration after five successive days of CRH pretreatment (100 $\mu$ g, i.v./ day) (closed).

isolated ACTH deficiency but also in type I diabetes mellitus. Although she was obese, no evidence of impaired glucose tolerance or decreased insulin sensitivity was detected, and there were no antibodies reactive to pituitary cells and pancreatic cells in our patient. A deficiency of $\mathrm{CRH}$ or abnormalities in the $\mathrm{CRH}$ receptor might also have been responsible for the isolated ACTH deficiency. Since human recombinant CRH successfully stimulated ACTH secretion from the pituitary in this patient, the $\mathrm{CRH}$ receptor at the corticotroph cells must be intact and functional. The CRH deficiency in the hypothalamus could also cause isolated ACTH deficiency. CRH deficiency was first described by Martin et al. [8] in three children. Since their report only four adult cases have been reported $[9,10]$, but the exact etiology of primary suprapituitary disorder remains unclear. Hashimoto's thyroiditis associated with this disorder in our patient suggests the possibility of an underlying autoimmune process in suprapituitary lesions. Interestingly, one of the previously reported cases of hypothalamic isolated ACTH deficiency also showed evidence of autoimmune thyroid disease [10]. Certain autoimmune processes may be associated with such pathways as $\mathrm{CRH}$ production, $\mathrm{CRH}$ secretion or $\mathrm{CRH}$ transfer.

Otherwise, hypofunctioned CRH neurons may cause autoimmune disease. An animal model with hypofunctional $\mathrm{CRH}$ neurons which responds poorly to all stimulatory neurotransmitters, and in 
which the overall HPA-axis response to stress is decreased, allows the development of autoimmune inflammatory phenomena [11]. Low CRH states also result in many behavioral effects such as fatigue, obesity, irritability, depression and so on. Some of them were seen in this patient.

Isolated ACTH deficiency sometimes shows a normal plasma ACTH level and variable (not specific) signs without typical adrenal crisis. Because it is difficult to diagnose such patients as having isolated ACTH deficiency, we must use some available tests for its precise diagnosis. The recent availability of recombinant human CRH provides a valuable tool for the investigation of hypothalamic-pituitary-adrenal axis abnormalities. Indeed the usefulness of the $\mathrm{CRH}$ test in distinguishing between suprapituitary and pituitary dysfunction has been already shown in a couple of studies $[4,5,12]$. Like these reports, clear ACTH response to $\mathrm{CRH}$ but not to hypoglycemia strongly suggests suprapituitary dysfunction in this case. Although we cannot completely exclude the possibility of "limited ACTH reserve", the findings of low UFC levels and apparent $\mathrm{ACTH}$ response to CRH seem to be incompatible with this condition. Delayed and exaggerated $\mathrm{ACTH}$ response to $\mathrm{CRH}$ in patients with hypothalamic disorders and no response in patients with pituitary defects have been found [5]. $\mathrm{CRH}$ may therefore be a useful tool to use in clarifying the responsible lesion in the syndrome of isolated ACTH deficiency. As shown in Fig.3, no apparently augmented and delayed peak of ACTH response to CRH was seen in our patient. The reason why augmented and delayed response was not seen may be due to a partial CRH deficiency, and the results of the CRH test, LVP test and ITT may provide more accurate information about the responsible lesion rather than those of the CRH test alone. The direct mesurement of circulating $\mathrm{CRH}$ may also be considered to be a good diagnostic marker of the $\mathrm{CRH}$ deficiency although we could not measure it in this patient.

In summary, we have reported on isolated ACTH deficiency possibly due to suprapituitary disorder. Although the exact mechanism of this abnormality remains unclear, $\mathrm{CRH}$ deficit in the hypothalamus is a possible explanation for these findings. In such patients as we reported here the term "isolated CRH deficiency" may be suitable for its diagnosis instead of isolated ACTH deficiency. Further clinical, immunological and molecular approaches are needed to clarify the pathophysiology of isolated CRH deficiency.

\section{References}

1. Steinberg A, Schecter FR, Segal HI (1954) True pituitary Addison's disease: A pituitary unitropic deficiency; fifteen years follow-up. J Clin Endocrinol Metab 14: 1519.

2. Yamamoto T, Fukuyama J, Hasegawa K, Sugiura $M$ (1992) Isolated corticotropin deficiency in adults. Report of 10 cases and review of literature. Arch Intern Med 152: 1705-1712.

3. Stacpoole PW, Interlandi JW, Nicholson WE, Rabin D (1982) Isolated ACTH deficiency: A heterogeneous disorder. Clinical review and report of four new cases. Medicine 61: 13-24.

4. Tsukada $T$, Nakai $Y$, Koh $T$, Tsujii S, Inada $M$, Nishikawa M, Shinoda H, Kawai I, Takezawa N, Imura $H$ (1984) Plasma adrenocorticotropin and cortisol responses to ovine corticotropin-releasing factor in patients with adrenocortical insufficiency due to hypothalamic and pituitary disorders. J Clin Endocrinol Metab 58: 758-760.

5. Fukata J, Nakai $Y$, Imura $H$, Abe K, Aono T, Demura H, Fujita T, Hibi I, Ibayashi H, Igarashi M, Irie M,
Izumi K, Kageyama N, Kato K, Kumahara Y, Matsuzaki F, Matsukura S, Miyai K, Mori S, Nakagawa K, Nakajima H, Niimi M, Ogata E, Saito S, Shimizu N, Shizume K, Takahara J, Takakura K, Tomita A, Uozumi T, Wakabayashi I, Yanaihara N, Yoshimi T, Yoshinaga K (1988) Human corticotropin-releasing hormone test in normal subjects and patients with hypothalamic, pituitary or adrenocortical disorders. Endocrinol Japon 35: 491-502.

6. Sauter NP, Toni R, McLaughlin CD, Dyess EM, Kriitzman J, Lechan RM (1990) Isolated adrenocorticotropin deficiency associated with an autoantibody to a corticotroph antigen that is not adrenocorticotropin or other proopiomelanocortinderived peptides. J Clin Endocrinol Metab 70: 1391-1397.

7. Sugiura M, Hashimoto A, Shizawa M (1986) Heterogeneity of anterior pituitary cell antibodies detected in insulin-dependent diabetes mellitus and adrenocorticotropic hormone deficiency. Diabetes 
Res 3: 111-114.

8. Martin MM, Martin ALA (1971) Idiopathic hypoglycemia. A defect in hypothalamic ACTHreleasing factor secretion. Pediatr Res 5: 396 (Abstract).

9. Orme SM, Belchetz PE (1991) Isolated ACTH deficiency. Clin Endocrinol 35: 213-217.

10. Velardo A, Pantaleoni M, Zizzo G, Del Rio G, Coletta F, Carani C, Marrama P (1992) Isolated adrenocorticotropic hormone deficiency secondary to hypothalamic deficit of corticotropin releasing hormone. J Endocrinol Invest 15: 53-57.

11. Chrousos GP, Gold PW (1992) The concept of stress and stress system disorders. Overview of physical and behavioral homeostasis. JAMA 267: 1244-1251.

12. Nakahara $M$, Shibasaki $T$, Shizume $K$, Kiyosawa $Y$, Odagiri E, Suda T, Yamaguchi H, Tsushima T, Demura H, Maeda T, Wakabayashi I, Ling N (1983) Corticotropin-releasing factor test in normal subjects and patients with hypothalamic-pituitary-adrenal disorders. J Clin Endocrinol Metab 57: 963-968. 